\title{
Sobre nuevas fábricas omeyas en el castillo de Medellín y otras similares de la arquitectura andalusí
}

\author{
Pedro Gurriarán Daza * \\ Samuel Márquez Bueno ***
}

\begin{abstract}
RESUMEN
A pesar de que el castillo de Medellín (Badajoz) se encuentra referido en las crónicas musulmanas desde un primer momento, los vestigios más antiguos, localizados hasta ahora, se reducían a un pequeño pero interesante aljibe atribuible a época almohade. Sin embargo, la novedosa identificación de ciertas fábricas en el frente septentrional de la fortaleza, de posible cronología omeya, constituye una gran ayuda a la sistematización de unos modos constructivos, muy concretos, cuyo desarrollo y difusión se extiende a determinadas zonas de las Marcas Inferior y Media de al-Andalus.
\end{abstract}

\section{PALABRAS CLAVES}

Técnicas constructivas, aparejo, omeya, Medellín, Extremadura

\begin{abstract}
RÉSUMÉ
Bien que le château de Medellín (Badajoz) soit mentionné par les chroniques musulmanes dès le VIlle siècle, les vestiges les plus anciens, connus jusqu'à présent, se résumaient à une petite, mais intéressante, citerne attribuable à l'époque almohade. Cependant, la toute nouvelle identification de constructions de possible chronologie omeyyade, localisées sur le front septentrional de cette forteresse, est d'une grande aide pour la systématisation de certaines techniques constructives qui se développèrent dans des zones restreintes des Marches inférieure et moyenne d'al-Andalus.
\end{abstract}

\section{MOTS CLEFS}

Techniques constructives, appareil, omeyyade, Medellín, Estrémadure

\section{INTRODUCCIÓN}

La población de Medellín (Badajoz) adquirió una importancia destacada durante la Antigüedad, cuando se desarrolló en su solar la ciudad romana de Metellinum. Las condiciones estratégicas de su emplazamiento, asociadas sobre todo al control del cercano paso sobre el Guadiana, fueron un factor decisivo en la preponderancia militar y económica que consiguió Medellín dentro del territorio en un primer momento '. Aunque las fuentes textuales islámicas se muestran más bien parcas con relación a Madallinn, confirman que el lugar se mantuvo en la Alta Edad Media al seguir asumiendo idénticos valores como nudo de comu-

* Instituto de Estudios Campogibraltareños, Yamur. Arquitectura y Arqueología S.L.

*** Yamur. Arquitectura y Arqueología S.L.

I Se refiere la importancia estratégica y económica que asumió el eje Medellín-Magacela en la región inmediata para el éxito de la romanización en P. ORTIZ ROMERO y A. RODRÍGUEZ DÍAZ, "La torre de Hijovejo: Génesis, evolución y contexto de un asentamiento fortificado en La Serena (Badajoz)", Torres, atalayas y casas fortificadas. Explotación y control del territorio en Hispania (S. III a. de C. - S. I d. de C.), Ed. P. Moret y T. Chapa, Jaén, 2004, p. 93. 
nicaciones de la antigua ruta que unía Mérida con Toledo y Zaragoza ${ }^{2}$. Por desgracia, estas citas y ciertos restos de cerámica son, en la actualidad, algunos de los escasos elementos de información que poseemos sobre el Medellín andalusí. Además, habríamos de añadir el aljibe de la fortaleza señorial, única construcción de época islámica conocida hasta ahora, que contrasta con los importantes vestigios arqueológicos romanos conservados en el cerro del castillo y su entorno.

El trabajo que presentamos en estas páginas trata sobre determinadas estructuras defensivas que forman parte del castillo de esta población, y cuyo origen relacionamos con una fase edilicia de época omeya. Estas fábricas se organizan mediante sillerías de acarreo y grandes mampuestos, rodeadas por anchas y cuidadas cintas de mortero, cuya puesta en obra será muy singular como tendremos ocasión de analizar. La presencia de aparejos similares en otras obras militares de al-Andalus, generalmente vinculadas por distintos autores a época emiral o califal, sugiere la cronología propuesta en estas líneas. Nuestra intención será, por consiguiente, no sólo dar a conocer esta etapa constructiva altomedieval del castillo de Medellín, sino, también, reflexionar sobre este tipo de fábricas que origina un singular conjunto dentro de la arquitectura andalusí.

\section{CONTEXTO HISTÓRICO Y ARQUEOLÓGICO}

Después de ser uno de los más importantes asentamientos protohistóricos del suroeste ibérico ${ }^{3}$, y uno de los principales centros de la romanización de la región durante el periodo republicano ${ }^{4}$, la fundación de Augusta Emerita relegó a Metellinum a un segundo plano, en el que se mantuvo tras la caída del Imperio. Al igual que ocurre en otros muchos lugares, el periodo visigodo constituye una gran incógnita histórica, aunque podemos suponer que la población permaneció en la misma situación hasta la invasión musulmana.

A partir de este momento, la trayectoria histórica de Medellín sólo se puede rastrear a través de datos puntuales aportados por diferentes fuentes textuales que no refieren ninguna información sobre su conquista por parte de los ejércitos de Mūsā. Los datos más antiguos ya nos muestran a esta población inmersa en la compleja situación política en la que se encontraban las Vegas del Guadiana durante el periodo emiral, y aluden de forma reiterada a la presencia de beréberes de la tribu Hawwāra. Este grupo ya estaba establecido a finales del siglo VIII, cuando el rebelde Šaqyà al-Mikāsī atacó el hișn al-Hawwārīyyīn ${ }^{5}$, llamado también Madāin, entonces bajo el mando del 'āmil Abū

\footnotetext{
2 Es muy probable que la expedición dirigida en 7/3/94H por Mūsā b. Nușayr desde Mérida a Toledo tomara el itinerario de origen romano señalado en el Itinerario de Antonino, que enlaza ambas localidades, y que discurre por las cercanías de Medellín. P. CHALMETA, Invasión e islamización. La sumisión de Hispania y la formación de al-Andalus, Madrid, 1994, p. I80. De igual modo, el geógrafo lbn Hawqal sitúa a esta población en la segunda mitad del siglo X entre Mérida y Trujillo, formando parte de un recorrido similar; información recogida en B. FRANCO MORENO y A. F. SILVA CORDERO, "Nueva propuesta de ubicación del emplazamiento bereber de Miknāsa en el țagr al-adnà o Frontera Inferior de al-Andalus", Mérida. Ciudad y Patrimonio. Revista de Arqueología, Arte y Urbanismo, №5, Mérida, 200I, pp. I6I y 162. Dos siglos más tarde, al-Idrīsī hace idéntica mención de Medellín y del itinerario que consideramos, y cuya arteria principal discurriría por Mérida, Medellín, Santa Cruz, Trujillo, Miknāsa, Majāḍat al-Balāț, Talavera y Toledo; véase, AL-IDRĪSĪ, Description de I'Afrique et de I'Espagne, Trad. R. Dozy y M. J. de Goeje, Amsterdam, reed. I969, pp. 226 y 227. Este itinerario es estudiado en F. HERNÁNDEZ GIMÉNEZ, "La küra de Mérida en el siglo X”, Al-Andalus, XXV, 1960, pp. 35 I y ss. En Medellín enlazaría en época musulmana otro camino que, proveniente de Córdoba, llegaría hasta Mérida; consúltese, F. HERNÁNDEZ GIMÉNEZ, "Los caminos de Córdoba hacia el noroeste en época musulmana", Al-Andalus, XXXII, 1967, pp. 277 y ss; además, refiere la importancia del tramo Mérida-Medellín-Trujillo en p.292.

3 M. ALMAGRO GORBEA, "El territorio de Medellín en época protohistórica", Économie et territoire en Lusitanie romaine, Ed. J.-G. Gorges y F. G. Rodríguez Martín, Coll. Casa de Velázquez N65, Madrid, 1999, pp. 17 a 38.

4 S. HABA QUIRÓS, Medellín romano. La colonia Metellinensis y su Territorio, Badajoz, 1998.

5 Este acontecimiento, ocurrido en 770/I53H, es relatado por IBN AL-ATīR, Annales du Maghreb et de l'Espagne, Trad. y notas E. Fagnan, Argel, 190I, pp. II 8 a 120, 125. Ajbār Maŷmüa, Crónica anónima del s. XI, Trad. E. Lafuente Alcántara, Colección de obras arábigas de Historia y Geografía de la Real Academia de la Historia, Madrid, I 867, pp. 99 y I00. IBN 'IDĀRT, Historia de al-Andalus, Trad. F. Fernández González, Málaga, 1999, pp. 81 y 82. Ver también, É. LÉVI-PROVENÇAL, Histoire de l'Espagne musulmane, París, reed. 1999, tomo I, pp. II2 a II4. E. MANZANO MORENO, La frontera de al-Andalus en época de los omeyas, Madrid, I99I, pp. 244 y 245.
} 
Za'bal al-Șadfūrī (de la familia Șadfūra, perteneciente a esta misma tribu). Posteriormente, Ibn Hazm ${ }^{6}$ cita a varios miembros de la familia de los Banū Farfarīn (también relacionados con los Hawwāra) como gobernadores (wāli $\bar{l}-s)$ de Madallin/Medellín 7 . Tanto éstos como otros relatos de distintos géneros describen este lugar como un hișn o fortaleza de la küra de Mérida ${ }^{8}$, a pesar de ser incluida como ciudad en la lista de Ibn Hawqal ${ }^{9}$, cuya interpretación es bastante confusa. La sumisión del Occidente de al-Andalus a 'Abd al-Rahmān III en 929930/317H acabó definitivamente con la influencia política de las tribus beréberes ${ }^{10}$. Una de las consecuencias de este cambio fue la desaparición de su topónimo de tipo tribal (hișn alHawwārìyiñ), pasando a usarse exclusivamente el de origen latino (Madallinn). Sin embargo, estas modificaciones políticas no provocaron la desaparición de todos los hușūn de la zona. Al contrario, algunos de ellos fueron conservados como elementos importantes para el control de la kūra de Mérida "I.

Las excavaciones realizadas en el teatro romano en la década de los setenta ${ }^{12}$ atestiguan, con la aparición de ataifores en verde y manganeso (entre los que destaca un ejemplar con decoración zoomorfa), candiles de piquera, etc. ${ }^{13}$, la ocupación del entorno de la for- taleza durante los siglos $X$ y XI (Fig. I). Otro dato de interés, que refleja el carácter del lugar durante el siglo XII, lo proporciona el geógrafo al-Idrisī, quien lo describe como "[...] una fortaleza bien poblada; sus caballeros y sus infantes hacen incursiones y razzias en el país de los cristianos" '14. Lo que si resulta evidente es que con la creciente amenaza cristiana la fortaleza va a ser remodelada (al igual que las de Magacela o Montemolín), tal y como nos muestran los restos de la torre de tapia de hormigón arrasada (véase infra). Estas obras se realizarían seguramente durante la época almohade, que está muy bien documentada a través del registro cerámico del teatro romano.

\section{DESCRIPCIÓN DEL CASTILLO}

El castillo de Medellín se eleva sobre un promontorio situado entre la población homónima, a mediodía, y el río Guadiana, al norte ${ }^{15}$. Al adaptarse a la topografía existente, su planta adopta una forma de polígono irregular muy próxima a una elipse, con sus ejes mayor y menor superando apenas los 160 y 80 m respectivamente (Fig. 2). La estructura general de la fortaleza se organiza mediante una muralla principal circundada en todo su perímetro, excepto en el tramo noreste, por una barre-

6 IBN HAZM, Ŷamharat ansāb al-'arab, Ed. 'A. S. M. Hārūn, El Cairo, 1962, pp. 499 y 500.

7 H. DE FELIPE RODRÍGUEZ, Identidad y onomástica de los beréberes de al-Andalus, Madrid, 1997, pp. 308 y 309.

8 AL-BAKRT̄, Kitāb al-masālik wa-l-mamālik, Trad. E. Vidal Beltrán, Geografía de España (Kitāb al-masālik wa-l-mamālik), Textos Medievales, 53, Zaragoza, 1982, p. 35. AL-HIMYARĪ, La péninsule ibérique au Moyen Age d'après le Kitāb ar-Rawd al-Mi'tār, Trad. E. LéviProvençal, Leiden, 1938, p. 252. YĀQÜTT, Mu'ğam al-buldān, Trad. 'Abd al-Karīm, "La España musulmana en la obra de Yāqūt", Cuadernos de la Historia del Islam, 6, 1974, p. 280. IBN HAYYĀN, Crónica del califa 'Abdarrahmān III an-Nāsīr entre los años 912 y 942 (al-Muqtabis V), Trad. M. J. Viguera y F. Corriente, Zaragoza, I98I, p. I0I. AL-IDRĪST̄, Nuzhat al-musțāq, Trad. fr. Chevalier A. Jaubert revisada por A. Nef, presentación H. Bresc y A. Nef, La première géographie de l'Occident, París, I999, p. 270.

9 IBN HAWQAL, Kitāb Șürat al-ard, Trad. M. J. Romani Suay, Configuración del mundo, fragmentos alusivos al Magreb y España, Textos Medievales, 26, Valencia, 197I, p. I5.

IO IBN H. AYYĀN, op. cit., 198I, pp. 182 a 184 (zona de Mérida) y 187 a 188 (Badajoz).

II La escasa eficacia de ésta y otras fortificaciones próximas se deriva del testimonio sobre la cabalgada del rey leonés Ordoño II por tierras extremeñas en 9/5-916/303H. En esta incursión, contra la cual no se opone resistencia, se transita por las inmediaciones de Medellín. Ibidem, p. 159.

12 M. DEL AMO y DE LA HERA, "El teatro romano de Medellín", El teatro en la Hispania Romana, Badajoz, 1982, pp. 317 a 322.

13 Material procedente de la excavación citada y conservado en el Museo Provincial de Badajoz.

14 AL-IDRĪST̄, op. cit., 1969, p. 226.

15 Las coordenadas U.T.M. de la base de la gran torre septentrional de la fortaleza son X, 243972; Y, 43।7506, Z, 312 m.s.n.m. 
ra exterior de menor elevación dotada puntualmente de torres de refuerzo. El interior del recinto queda estructurado a partir de dos espacios adyacentes y segregados por un muro diafragma que enlaza dos importantes torres cuadrangulares; éstas aparecen emplazadas, aproximadamente, en los puntos medios de los lienzos septentrional y meridional. Otras torres de planta semicircular flanquean el resto del muro principal cada cierto trecho. Los accesos a la fortificación se realizan a través de sendas estructuras en codo situadas en los frentes septentrional y meridional del antemuro. La definitiva comunicación con el interior de la fortaleza se logra mediante sencillas puertas practicadas junto a las grandes torres referidas, y mediante otra de similares características abierta en el frente occidental. De todos estos accesos, nos interesa especialmente el acodado contiguo a la torre norte, pues en su reedificación se aprovecharon algunas de las estructuras islámicas objeto de nuestro estudio.

Las primeras obras de reforma realizadas a partir de la conquista cristiana de 1234 nos son prácticamente desconocidas, pero, en cualquier caso, no debieron de ser profundas, por lo que es bastante probable que la fortaleza musulmana llegase a 1354 en buen estado de uso. Tras su destrucción en ese último año, las labores de refundación se posponen hasta 1373; a pesar de que a ese momento pertenece el grueso de la obra que aún perdura, se ejecutarán sucesivas e importantes modificaciones durante el siglo XV y principios del siguiente, coincidiendo con su auge como sede nobiliaria ${ }^{16}$. En todas estas intervenciones predominan, de forma masiva, las fábricas de mampostería careada tomadas con mortero de cal. Los sillares se reservan únicamente para elementos puntuales y destacados como aristas de torres, estructuras de puertas o ménsulas de matacanes.
Al margen de estas obras de cronología bajomedieval, los restos conservados de origen andalusí son más bien escasos y aparecen localizados de modo disperso. El más conocido es el interesante aljibe de dos naves adosado al lienzo meridional del castillo, a occidente de la torre del homenaje referida como cuadrangular sur ${ }^{17}$. Además de las fábricas omeyas que presentamos en estas páginas, merece la pena referir cómo el gran bastión de planta ultrasemicircular situado en el extremo oriental del recinto se edifica sobre un potente macizo cuadrangular de tapia hormigonada que, por sus características, bien pudiera pertenecer a la base de una torre defensiva de época almohade arrasada.

\section{LAS FÁBRICAS DE ÉPOCA OMEYA DEL CASTILLO DE MEDELLÍN}

\section{I. Definición de las estructuras}

Como se ha apuntado en líneas precedentes, las principales estructuras que configuran el actual castillo de Medellín presentan un alto grado de homogeneidad y un similar concepto tecnológico. El estudio de sus paramentos apunta en ese sentido, y a pesar de las necesarias remodelaciones puntuales de mejor o peor puesta en obra, las técnicas constructivas asociadas a las reformas cristianas de la fortaleza serán claramente reconocibles, y sobre todo, predominantes en el conjunto. Los aparejos de mampostería careada y mortero calizo son habituales en estas estructuras, y al igual que ocurre en otras construcciones coetáneas asociadas a la poliorcética castellano-leonesa, se dotarán en puntos singulares de piezas de cantería.

Dentro de este contexto constructivo tan homogéneo, la presencia puntual de algunas fábricas completamente diferentes, y amortizadas

\footnotetext{
16 Sobre la evolución bajomedieval de la fortaleza de Medellín, consúltese, S. ANDRÉS ORDAX et alii, Testimonios artísticos de Medellín, Salamanca, 1985, pp. 51 y ss.

17 Se argumenta tal atribución en ibidem, pp. 61 a 63. Aun así, creemos que otro elemento de datación podría aportarlo la nacela que se forma en el retranqueo del alfiz en cada faz de la bífora.
} 
por estos calicantos de cronología bajomedieval, aportará una mayor riqueza al análisis estratigráfico. Además, permitirán arrojar dataciones previas a la conquista de 1234, que constituye un terminus ante quem. Las particulares características formales y de puesta en obra que presentan estos materiales permitirán afinar su posible cronología, sobre todo en virtud a su relación con un marco tecnológico determinado dentro de la construcción andalusí. En cualquier caso, se tendrá en cuenta que los márgenes temporales propuestos serán siempre relativos y no absolutos. Así, el simple análisis de las fábricas de la desaparecida fortificación islámica, sin otros elementos o ejemplos complementarios que nos confirmen fechas exactas, dejará abierto un cierto margen temporal de difícil cuantificación.

El primer elemento a destacar es el basamento sobre el que se alza la torre del espolón occidental; ambos difieren tanto en su trazado -planta ultrasemicircular sobre planta cuadrangular- como en el material empleado para su construcción -mampostería sobre tapia hormigonada. Esta fábrica encofrada o țābiya, muy bien trabajada y con alta proporción de cal, será característica de la arquitectura almohade ${ }^{18}$. La lista de paralelos para estas fábricas es larga, pero referiremos en la propia región las tapias de los recintos de la alcazaba de Badajoz, Cáceres o Reina. De este modo, estaríamos hablando de los restos de una gran torre reformada o añadida por las autoridades muminíes, posteriormente demolida (ital vez en la gran destrucción de mediados del siglo XIV?) y suplantada por la actual construcción. Esta estructura la relacionamos con el aljibe del interior de la fortaleza, que por sus características formales y tipológicas se puede relacionar sin problemas con la edilicia almohade.
Pero los restos sobre los que trata este estudio son ciertas fábricas que se identifican en la zona septentrional del castillo. Aparecen en la torre que organiza el paso acodado situado en el antemuro, y en la base de la vecina torre cuadrangular de la fortaleza. En ambos casos, son empleados grandes sillares graníticos de medidas variables, pero cuya altura se establece en torno a 50-55 cm. Las piezas se aparejan de forma desordenada a soga y tizón, aunque siempre se tratará de buscar un correcto nivelado de cada hilada; esta circunstancia evita que aparezcan engatillados en los sillares. Es evidente su origen de acarreo derivado del saqueo de edificios de la antigua Metellinum. Asociados a estas sillerías, y en menor cantidad, son usados grandes mampuestos o bloques careados de piedra cuarcítica, de mucho mayor formato que los vistos en los calicantos bajomedievales. El orden que se intenta establecer sitúa los sillares de forma preferente en la base de los muros, o en las aristas, utilizando la mampostería para completar determinadas hiladas. Su organización revela que este último material se emplea secundariamente, dependiendo de la puesta en obra de las piezas reutilizadas de cantería.

La formalización de estas fábricas posee la peculiaridad de que todos los elementos son sistemáticamente recalzados mediante abundantes ripios y fragmentos de pizarra. Pero la definitiva puesta en obra se logra tras la cubrición de llagas y tendeles por gruesas capas de mortero muy rico en cal, como continuación del que liga las piezas, de forma que queda definido un ancho y allanado encintado en el que asoman delgadas placas de pizarra dispuestas siempre de cara. Los filos de estas cintas que rodean a los sillares y grandes mampuestos, y que los unifica como una misma construcción, están cuidadosamente biselados

18 Consúltese, P. GURRIARÁN DAZA y A. J. SÁEZ RODRÍGUEZ, "Tapial o fábricas encofradas en recintos urbanos andalusíes", Actas del II Congreso Internacional "La Ciudad en al-Andalus y el Magreb" (Algeciras, noviembre 1999), Granada, 2002, pp. 603 a 6I4. Asimismo, R. AZUAR RUIZ, "Aspectos simbólicos de la arquitectura militar almohade. El falso despiece de sillería y las bóvedas de arcos entrecruzados", Actas del seminario "Los Almohades. I. Los vectores del mensaje almohade" (Madrid, 2000), en prensa; del mismo autor, R. AZUAR RUIZ, "Técnicas constructivas y fortificación almohade en al-Andalus", Actas del seminario "Los almohades. Su patrimonio arquitectónico y arqueológico en el Sur de al-Andalus" (Sevilla, 2003), en prensa. 
(Fig. 3). Estas interesantes fábricas son consecuencia de un método extremo para economizar material a la hora de proteger los paramentos; así, el mortero sólo se aplicará en aquellas áreas más débiles, las juntas entre piezas, evitando el recurso de un revestimiento continuo sobre toda la superficie.

Para una mejor descripción de todas estas estructuras, procederemos a sistematizarlas según el siguiente esquema dependiendo de su situación:

\section{A.- Torre del acceso acodado en el ante- muro septentrional (Fig. 4 y Láms. I y 2)}

A. I.- Frente Norte (lado total: 5,93 m): Se conservan cinco hiladas. Se describen de abajo a arriba, y de izquierda a derecha: ${ }^{a}$ Hilada (Soga-soga-tizón-soga-tizón-tizón), $2^{a} \mathrm{H}$ (T-S-S-T-S-iT?-S), $3^{\text {a }}$ H (T-T-S-S-T-S-S-S-T), $4^{\text {a }}$ H (S-S-T-S-S-T-S), $5^{\text {a }} \mathrm{H}$ (Incompleta, ...-T-S¿T?-iT?-..., incompleta).

A.2.- Frente Este (lado total: 7,67 m): Se conservan siete hiladas. Se organizan como sigue: I ${ }^{a} \mathrm{H}$ (Oculta, ...-S-S-S-..., oculta), $2^{\text {a }}$ H (T común $3^{a}$ H-iT?-T-S-T-S-S-..., oculta), $3^{a} \mathrm{H}$ (T común $2^{a} \mathrm{H}-\mathrm{S}-\mathrm{S}-\mathrm{S}-\mathrm{S}-\mathrm{T}-\ldots$... oculta), $4^{\text {a }} \mathrm{H}$ (S-S-T-S-S-T-S- ..., oculta), $5^{\mathrm{a}} \mathrm{H}$ (T-ST-S-T-S-S-..., oculta), $6^{a} \mathrm{H}$ (S-S-S- $i S$ ?..., incompleta), $7^{\text {a }} \mathrm{H}$ (T-Bloque Cuarcita-..., incompleta).

A.3.- Frente Sur (lado total: 6,21 m): Se conservan seis hiladas. Se organizan como sigue: $I^{\mathrm{a}} \mathrm{H}$ (Oculta, ...-S), $2^{\mathrm{a}} \mathrm{H}$ (Oculta, ...-T), $3^{\mathrm{a}}$ H (Oculta, ...-iS?-S), $4^{\text {a }} \mathrm{H}$ (Oculta, ...-BCBC-S-S-T), $5^{\text {a }} \mathrm{H}$ (Oculta, corresponde a la $7^{\mathrm{a}} \mathrm{H}$ de A.2., ...-BC-BC-BC-S), $6^{\mathrm{a}} \mathrm{H}$ (S-BC$B C-B C-B C-B C-B C-. .$, incompleta).

A.4.- Frente Oeste (lado total: 7,56 m): Se conservan siete hiladas. Se organizan como sigue: $I^{a} \mathrm{H}$ (Corresponde a la I ${ }^{\mathrm{a}} \mathrm{H}$ de A. I. S-..., oculta), $2^{a} H$ (T-S-iT?-.., oculta), $3^{\text {a }}$ H (S-T-..., oculta), $4^{\text {a }} \mathrm{H}$ (T-S-S-T-iS? ..., oculta), $5^{\text {a }} \mathrm{H}$ (Incompleta, ...-T-S-S-S-..., oculta), 6 $\mathrm{H}$ (Incompleta, ...-S-S-T-S-..., oculta), $\quad 7^{\mathrm{a}} \quad \mathrm{H} \quad$ (Incompleta, ...-S-BC-BC-iT?-BC-..., oculta).
Todas estas hiladas apoyan sobre un macizo rocoso apenas alterado, de modo que se recurrirá a lajas y pequeños mampuestos para regularizar la superficie base, como vemos en el frente septentrional de la torre. La primitiva estructura islámica es luego recrecida de forma irregular, siguiendo el desigual desmochado de las fábricas, mediante la habitual técnica de mampostería tomada con mortero de cal que predomina en la fortificación cristiana. La reforma se termina con el replanteo del parapeto y el almenado en los frentes oeste y norte, con una altura total en su cara septentrional de 7,50 m hasta el remate del pretil. Esta importante intervención se inscribe en la construcción de un acceso acodado en el antemuro que rodea a la fortaleza. Para ello es adosado a levante de la torre un pequeño recinto descubierto, en cuyo muro este se abre un arco rebajado de acceso. En la actualidad el interior aparece parcialmente colmatado de tierra, sobre todo en la zona de comunicación con la liza.

\section{B.- Torre cuadrangular septentrional de la fortaleza (Lám. 3)}

B. I.- Frente Norte (lado total: 6,00 m): Se conservan cinco hiladas. Se organizan como sigue: $I^{a} \mathrm{H}$ (Oculta, ...-BC-BC-BC-BC-BCS-T), $2^{\text {a }} \mathrm{H}$ (Oculta, ...-BC-S-S-T-T-S-S-S), $3^{\text {a }}$ $H$ (T-S-S-S-T-S-S-T), $4^{\text {a }} H$ (S-S-S-T-S-S-S), $5^{\text {a }}$ $H$ (T-S-BC-BC-BC-BC-S-T).

B.2.- Frente Este (lado parcial: 9,00 m): Se conservan cinco hiladas. Se organizan como sigue: ${ }^{a} \mathrm{H}$ (Corresponde a la $3^{\mathrm{a}} \mathrm{H}$ de B. I., oculta ...-S), $2^{\text {a }} \mathrm{H}$ (Oculta,...-BC-iT?-BC-BCBC-S-S-T), $3^{\mathrm{a}} \mathrm{H}$ (Incompleta, ... -BC-BC-BCBC-BC-BC-BC-BC-BC-BC-S), $4^{\mathrm{a}} \mathrm{H}$ (Incompleta, ...-BC-BC-BC-BC-..., incompleta), $5^{a}$ $H$ (Incompleta, ...-BC-BC-BC-..., incompleta).

B.3.- Frente Oeste (lado parcial: 4,75 m): Se conservan seis hiladas. Se organizan como sigue: $I^{a} \mathrm{H}$ (Corresponde a la $\mathrm{I}^{\mathrm{a}} \mathrm{H}$ de B.I. S-..., oculta), $2^{\text {a }} \mathrm{H}$ (T-.., oculta), $3^{\mathrm{a}} \mathrm{H}$ (S..., oculta), $4^{\mathrm{a}} \mathrm{H}$ (T-iS?..., oculta), $5^{\mathrm{a}} \mathrm{H}$ (SBC-..., incompleta), $6^{\mathrm{a}} \mathrm{H}$ (Incompleta, ...-BCBC-BC-BC-..., oculta). 
No es posible confirmar la existencia de fábricas similares en el frente meridional de la torre debido a la importante colmatación de tierras del interior de la fortaleza. Hemos de destacar cómo los restos conservados en la base de esta gran construcción presentan un mayor deterioro que los vistos en la estructura acodada, al haber sufrido una pérdida importante de las bandas de cal que recercan los sillares. De este modo, las piezas aparecen desnudas y con las piezas de recalzo visibles. El arrasamiento de la primitiva obra islámica fue sistemático, y es difícil siquiera asegurar una planta aproximada de la misma, pues sólo se identifican las aristas correspondientes al frente septentrional. En cualquier caso, los restos serán reaprovechados como basamento de la imponente torre cristiana, de tres niveles, que actualmente se alza en el lugar. Esta reforma se realiza siguiendo el procedimiento constructivo ya visto en el resto del castillo, y así las mamposterías careadas quedarán confinadas entre las cadenas de sillares que resuelven los ángulos.

\subsection{Encuadre cronológico. Fábricas recalzadas y encintadas con mortero en la arquitectura militar andalusí}

Planteamos en líneas precedentes la peculiaridad que presentan estas últimas estructuras con relación al resto de la construcción bajomedieval del castillo. La propia estratigrafía de los paramentos, y las especiales características de las fábricas, insisten en considerarlas anteriores a aquellas reformas. Ahora bien, esta cronología relativa se ve falta, en un primer momento, de criterios fiables para establecer otra de tipo absoluto, dada la lamentable ausencia de elementos de análisis que redunden en fechas concretas. A falta de testimonios epigráficos $y$, sobre todo, de profundos trabajos arqueológicos, hemos de centrarnos en el estu- dio de los métodos constructivos, y su formalización en un aparejo singular, para tratar de encuadrar el origen de las estructuras que las albergan dentro un sistema técnico preciso.

Comprender el desarrollo histórico de un edificio o construcción mediante el simple estudio de sus técnicas edilicias es una tarea delicada que ha de ser muy escrupulosa en aquellos casos en los que faltan jalones temporales exactos. Así, insistiremos en la relatividad de los estudios de aparejos como método definitorio per se para concretar dataciones, al menos en aquellos casos en los que se obvia la pertenencia del edificio, como unidad, a un sistema más general. Estos modelos sintéticos deben comprender las técnicas de construcción como el resultado de un ciclo productivo concreto, que será característico de ciertos elementos pertenecientes a un "medio" o entorno socio-cultural, más o menos desarrollado tecnológicamente.

Con relación a estas fábricas de Medellín, y más allá de la información puntual que proporciona el propio estudio de estratos parietales, es posible identificarlas con un sistema o modelo constructivo que aparece en un grupo de fortificaciones andalusíes de época omeya. Como veremos a continuación, empleamos el término tan vago de "omeya" dada la cronología incierta entre lo emiral y califal que se suele adjudicar a estas edificaciones en diversos estudios. Nos referimos a fábricas recalzadas que se rodean con cintas de mortero calizo como continuación del que liga las piezas, y que incluyen pequeños fragmentos pétreos colocados de cara.

El primer y más importante paralelo, dada su gran semejanza y proximidad geográfica, será el del castillo de Trujillo (Cáceres), fechado por diversos estudios en el periodo considerado ${ }^{19}$.

19 Sobre este castillo, véase J. LAFUENTE y J. ZOZAYA, "Algunas observaciones sobre el castillo de Trujillo". España entre el Mediterráneo y el Atlántico. Actas del XXIII Congreso Internacional de Historia del Arte (Granada, 1973), II, Granada, 1976, pp. II 9 a 127, se defiende una cronología de finales del siglo IX en p. 123. Se propone como límite para la fundación del castillo, debido a ciertos aspectos edilicios, los primeros años del siglo X en F. VALDÉS FERNÁNDEZ, "La fortificación islámica en Extremadura: Resultados provisionales de los trabajos en las alcazabas de Mérida, Badajoz y Trujillo y en la cerca urbana de Cáceres", Extremadura Arqueológica, II, I99I, p. 550; este mismo autor sugiere una datación emiral en F. VALDÉS FERNÁNDEZ, "El urbanismo islámico de la Extremadura leonesa: Cuatro pautas de desarrollo", Genèse de la ville islamique en al-Andalus et au Magreb Occidental, Madrid, 1998, p. 180. 
La obra fundacional se levanta con sillares de acarreo de muy diversa metrología y con grandes bloques de labra irregular trabajados ex profeso. Estas piezas graníticas son encintadas con las referidas bandas de cal que incluyen placas de pizarra, y como sucede en las estructuras de Medellín, se cuida su puesta en obra con detalles como el biselado de los bordes de las cintas (Fig. 5 y Lám. 4) ${ }^{20}$. El posterior y definitivo recrecido que sufrirá la fortaleza empleará otras fábricas bien distintas de sillarejo y mampostería más menuda.

Asimismo debemos referir el caso de Toledo, en cuyas puertas del Cambrón (Bāb alYahūd) y de Alcántara (Bāb al-Qantāra) aparecen restos muy deteriorados de cinta de cal con inclusiones de placas de pizarra que recercan sillares reaprovechados de obras preislámicas. Estas fábricas se sitúan, respectivamente, en el frente exterior de las dos torres que flanquean el acceso ${ }^{21}, y$ en el corredor que se abre una vez superado el primer codo exterior, justo encima de un doble desagüe de la muralla (Lám. 5). En la puerta de Alcántara están recrecidas con mampostería encintada con ladrillo, posiblemente de los siglos XIII o XIV según Torres Balbás ${ }^{22}$, aunque en otros trabajos se estudien fábricas similares como anteriores ${ }^{23}$. En cualquier caso, es difícil referir el origen de ambas puertas toledanas, pero tal vez podamos identificar la segunda de ellas con las obras del al-hizām erigido por el califa al-Nāșir en 932/320H 24; como cita Ibn Hayyān, "disponiendo él mismo allí el alcázar de caídes y gobernadores, que está junto a la puerta del puente [Bāb al-Qantāra] en el lugar llamado el ceñidor [al-ḥizām], de sólida construcción, [...] pues el 'ceñidor' lo separa de la ciudad y lo conecta a la puerta del puente, haciendo una sola de la de éste y la del alcázar [...]” 25. De este modo, dicha puerta tendría claros fines estratégicos al comunicar la alcazaba omeya con el puente sobre el río Tajo ${ }^{26}$.

Dos casos singulares que presentan algunas variaciones dentro de esta técnica lo constituyen Vascos (Navalmoralejo, Toledo) y Talavera (Toledo). En el primero de ellos, concretamente en el amplio recinto que rodea la madina, aparecen de forma puntual elementos colocados de plano sobre cintas biseladas, pero estos fragmentos serán a menudo de naturaleza cerámica (Lám. 6). De todos modos, quedaría por aclarar ciertas disparidades constructivas señaladas en fábricas de otros lienzos (ital vez distintos equipos?), como ocurre con el empleo de morteros de peor puesta en obra. En cualquier caso, la cronología de esta fortificación no está clara, pero en los últimos trabajos de Ricardo Izquierdo se viene asignando una datación califal a la cerca urbana, diferenciándola de la alcazaba, que sería en su origen un hișn emiral ${ }^{27}$. La alcazaba de Tala-

\footnotetext{
20 La existencia de una solución más pobre en la epidermis de las torres albarranas que se adosan al recinto, sin el biselado de las cintas, tal vez sirva para reflexionar sobre la discutida cronología de las mismas. Con relación a las albarranas de Trujillo, y a la existencia de torres adelantadas en la arquitectura militar andalusí de los primeros siglos, consúltense las tesis contrapuestas en los estudios de J. ZOZAYA, “'Fortificaciones tempranas?", Actas del I Congreso de Castellología Ibérica, Palencia, I994, pp. I08 y I09; y, por otra parte, de F. VALDÉS FERNÁNDEZ, op. cit., 1998, pp. 181 y 182.

21 Los restos citados de la puerta del Cambrón de Toledo desaparecieron, lamentablemente, durante las últimas labores de restauración del monumento.

22 L. TORRES BALBÁS, “Arte hispanomusulmán hasta la caída del califato de Córdoba", España Musulmana hasta la caída del califato de Córdoba (7/ I-103 I). Historia de España, Dir. R. Menéndez Pidal, tomo V, Madrid, 1957, p. 635.

$23 \mathrm{Sin}$ ir más lejos, la propia mezquita del Cristo de la Luz, fechada en 999-1000/390H, presenta estas mamposterías encintadas con ladrillo. Por otra parte, se hace mención a estos aparejos de los siglos X y XI en B. PAVÓN MALDONADO, "Hacia un tratado de arquitectura de ladrillo árabe y mudéjar", Actas del III Simposio Internacional de mudejarismo (Teruel, septiembre 1984), Teruel, 1986, pp. 338 y 339.

24 IBN H.AYYĀN, op. cit., 1981, pp. 240 y 241.

25 Ibidem, p. 240.

26 Sobre la puerta de Alcántara y el al-ḥizām de Toledo, consúltese el estudio de C. DELGADO VALERO, "La estructura urbana de Toledo en época islámica", Regreso a Tulayțula. Guía del Toledo Islámico. Siglos VIII-XI, Toledo, I999, pp. 42 y ss.

27 Se refiere una autoría califal del recinto de la madina de Vascos en R. IZQUIERDO BENITO, La ciudad hispanomusulmana de Vas-
} cos. Navalmoralejo (Toledo), Toledo, 2000, p. 104. 
vera, aunque muy maltratada, aún muestra en sus muros estas estructuras que comentamos. Los restos mejor conservados se presentan en el lienzo meridional, concretamente en la torre situada en el extremo suroriental del recinto (Lám. 7). En este caso, las bandas de mortero calizo incluirán ocasionalmente placas pétreas o cerámicas, y rodearán, a veces biseladas, las piezas de recalce y los sillares de acarreo . Sobre esta obra se conserva una interesante cita de Aḥmad al-Rāzì que menciona su construcción o reconstrucción por 'Abd alRaḥmān III en 936-937/325H ${ }^{29}$.

En otras fortificaciones andalusíes identificamos fábricas recalzadas que siguen el esquema básico de las vistas anteriormente, pero que evidencian mayor pobreza de materiales y/o menor cuidado en la ejecución. En todas ellas las piezas son rodeadas con irregulares bandas de mortero, sin biselar, las cuales, además, no suelen incluir fragmentos planos como veíamos en los ejemplos anteriores. Siguiendo este procedimiento técnico encontramos un grupo de fábricas que se localizan en algunos lienzos del recinto urbano de Coria (Cáceres) o la alcazaba de Mérida (Badajoz) ${ }^{30}$, y en otros de las fortificaciones de Castros (Villar del Pedroso, Cáceres), Alija (Talavera la Vieja, Cáceres) o Espejel (Valdelacasa de Tajo, Cáceres) ${ }^{31}$.
Todas las obras defensivas citadas se sitúan en una amplia zona alrededor del eje MéridaToledo, que formaba parte de las Marcas Inferior y Media en torno a los cauces de los ríos Guadiana y Tajo. Esta distribución espacial tan precisa define un evidente carácter sectorial de estas prácticas constructivas ${ }^{32}$, las cuales influirán poco en el resto del territorio, sobre todo en el caso de las cintas que incluyen fragmentos cerámicos o esquistosos puestos de cara. Es difícil concretar el sincronismo exacto de todos estos restos, pues nos falta mucha información de calidad para llegar a cualquier conclusión definitiva, pero los escasos elementos de análisis nos presentan su origen a lo largo de una horquilla temporal que abarca desde el Emirato al Califato.

En cualquier caso, es importante constatar cómo el sistema de recalzar y luego encintar con bandas de mortero es el que define la técnica, pues el "contenido" variará, dependiendo de las posibilidades de recogida de material, desde sillares reutilizados (Toledo, Coria, Medellín, por ejemplo) hasta simples mampuestos o sillarejos en las obras más modestas. El predominio de la práctica del acarreo en la mayoría de estas estructuras nos habla bien claro de una cierta desestructuración de los ciclos productivos de la cantería, al reducirse los mismos

28 No obstante, en distintos muros y torres de la cerca urbana de Talavera aparecen discretos restos de morteros calizos tomando las piezas de sillería reutilizada y los elementos de recalzo, aunque sin llegar a formar cuidadas cintas. Estas estructuras se datan en tiempos del emir Muh_ammad I en S. MARTínEZ LILLO, Arquitectura militar andalusí en la Marca Media. El caso de Talabira, Talavera de la Reina, 1998, p. 360.

29 A. AL-RĀZ̄i, “Manuscrito de Copenhague” en Crónica del moro Rasis, Ed. D. Catalán y M. S. de Andrés, Madrid, 1975, p. 300. Sobre esta construcción véase S. MARTíNEZ LILLO, op. cit., 1998, pp. 41 y ss, especialmente sobre la datación de la alcazaba p. 6I, nota 57.

30 Con carácter excepcional, hemos localizado restos de un mortero que incluye algunos fragmentos de pizarra colocados de plano en la cara oriental de la torre del ángulo NE de la alcazaba de Mérida. Estas fábricas forran y recrecen parcialmente a las originales de época emiral $(835 / 220 \mathrm{H}$, fecha que se lee en la lápida fundacional de la fortaleza. E. LÉVI-PROVENÇAL, Inscriptions arabes d’Espagne, Leiden-París, I931, pp. 49 a 53).

3I S. MARTÍNEZ LILLO, op. cit., 1998, p. 59. Además, F. JIMÉNEZ DE GREGORIO, "Fortalezas musulmanas en la línea del Tajo", AlAndalus, XIX, 1954, pp. 410 a 420. J. JIMÉNEZ GADEA, "La 'atalaya' del Castillo del Marco (Villar del Pedroso, Cáceres)", Actas del IV Congreso de Arqueología Medieval Española, tomo II, Alicante, 1993, pp. 373 a 379. Y, sobre todo, S. MARTíNEZ LILLO y L. SERRANO-PIEDECASAS FERNÁNDEZ, "El poblamiento andalusí en al-Tagr al-Awsaț (Marca Media). El Mundo Omeya", Castillos y territorio en al-Andalus (Berja, 1996), Granada, 1998, pp. 71 a II5.

32 La existencia de distintos modos de poner en obra la sillería, y su distribución geográfica, ya fueron sintetizados de forma genérica por Juan Zozaya en diversos artículos. Véanse, por ejemplo, J. ZOZAYA, op. cit., 1994, pp. 78 y ss; y J. ZOZAYA "Fortificaciones tempranas en al-Andalus", Mil anos de fortificaçoes na Península Ibérica e no Magreb (500- I500), Lisboa, 2002, pp. 45 a 58. De igual modo, consúltese, por su carácter sintético, P. CRESSIER y M. C. DELAIGUE, "Modes architecturaux et modes architecturales: remarches sur l'architecture médiévale de pierre (al-Andalus et Magrib al-Aqs_)", Actas del simposio "De la sociedad islámica a la feudal. Veinte años de al-Andalus", (Granada-Valencia, mayo de 1996), en prensa. 
a la simple extracción, transporte y puesta en obra del sillar preislámico ${ }^{33}$; además, el uso complementario en Medellín de grandes bloques de cuarcita, con la única y torpe labra de su cara exterior, determina el escaso grado de desarrollo de estos constructores en el trabajo de la piedra sin expoliar. Sólo se puede insinuar una cierta especialización en la posterior labor de puesta en obra de las cintas de mortero de cal cuando éstas están bien trabajadas y terminadas con un cuidado biselado. Este último aspecto supone una mejora con respecto a los trabajos de simple recalce de las piezas, aunque no sabemos si es producto bien de una pura evolución técnica, bien de la existencia en esas obras de mayores medios.

Por otra parte, quedaría por definir quién promueve estas edificaciones, y en definitiva, cómo se termina de comprender el proceso constructivo en su conjunto desde el encargo hasta la ejecución. Y a este respecto hemos de reconocer que sabemos más bien poco. Las crónicas andalusíes que tratan sobre la periferia durante este periodo suelen hacerlo casi exclusivamente con relación a obras oficiales, y aún en ese caso, los técnicos y operarios encargados de las mismas suelen representar auténticos desconocidos ${ }^{34}$. Así, es complicado establecer el carácter exacto de los talleres que aquí definimos y la hipotética relación que pudieran tener con el poder. La costumbre de la autoridad emiral y califal de recurrir a especialistas y técnicas de índole local en distintas áreas de al-Andalus ya fue planteada por uno de los autores en un estudio reciente, y es así como resolverían numerosas promociones en el ámbi- to de la frontera ${ }^{35}$. De este modo, la información epigráfica disponible sobre la alcazaba emeritense y la textual referente a las supuestas obras de Talavera y Toledo, que las relaciona con la iniciativa oficial, tal vez sirva para sugerir dicho origen puntual para estas fábricas, pero siempre quedaría la duda sobre la autoría de las demás obras, sobre todo de las más pobres. Se podría plantear una hipótesis que vincule materiales nobles-origen oficial y materiales pobres-origen no oficial, no obstante, y aunque a menudo es así, creemos que en estos medios poco desarrollados la calidad de las técnicas es consecuencia de la disponibilidad de los recursos materiales y la capacidad de trabajo sobre los mismos, más allá de la naturaleza del promotor. En definitiva, la única conclusión que podemos plantear a propósito de estas cuestiones, tal y como apuntamos, es que la localización tan precisa del conjunto de estas prácticas definirá completamente el carácter regional de los técnicos y talleres encargados de estas construcciones a lo largo del periodo propuesto.

\section{CONCLUSIONES}

El actual castillo de Medellín, a pesar de ser el resultado de los homogéneos trabajos de reforma llevados a cabo tras la conquista cristiana, aún conserva escasos pero significativos restos de su pasado andalusí. Entre ellos destacan ciertas fábricas pétreas que se observan integradas en el frente septentrional de la fortaleza. Estos vestigios se resuelven mediante masivos sillares graníticos de acarreo y bloques

\footnotetext{
33 Esta ruptura en los ciclos técnicos de la cantería será un fenómeno que se produzca en el conjunto del Mediterráneo Occidental desde la tardoantigüedad, y que aún se manifiesta durante la Alta Edad Media. Sobre estos temas, véanse, por ejemplo, J. A. QUIRÓS CASTILLO, "La sillería y las técnicas constructivas medievales: historia social y técnica de la producción arquitectónica", Archeologia Medievale, XXV, 1998, pp. 235 a 246; J. A. QUIRÓS CASTILLO, "La sillería en la arquitectura altomedieval en el Mediterráneo occidental", Actas del V Congreso de Arqueología Medieval Española, Vol. 2, Valladolid, 2002, pp. 28I a 29 I.

34 Con relación al Califato, resulta excepcional la referencia que nos ofrece lbn Hayyān sobre el envío por parte de 'Abd al-Raḥmān III de un protoarquitecto y varios operarios a su aliado norteafricano Mūsá b. Ảbī-l-ā́lya, IBN HAYYĀN, op. cit., I98I, p. 290. Por otra parte, la gran complejidad de la construcción en estos medios oficiales se deja entrever en otras informaciones, como la que menciona Ibn 'Idārī a propósito de la reconstrucción de Medinaceli por Gālib b. 'Abd al-Raḥmān III en 946/335H, la cual se acomete por albañiles de la frontera; consúltese, E. MANZANO MORENO, Op. Cit., 199|, p. I54.

35 P. GURRIARÁN DAZA, "Hacia una construcción del poder. Las prácticas edilicias en la periferia andalusí durante el Califato", Actas de las IV Jornadas de Madinnat al-Zahrā’ (Córdoba, noviembre de 2003), Cuadernos de Madinnat al-Zahrā', N 5, Córdoba, 2004, pp. 297 a 325.
} 
de cuarcita, recalzados, y rodeados de anchas bandas de mortero de cal. La singularidad de la técnica con la que se construyen reside, precisamente, en la puesta en obra de estos cuidados encintados, que presentan detalles como los bordes biselados o la inclusión de fragmentos de pizarra puestos de plano.

En ausencia de datos definitorios derivados de las fuentes medievales, la epigrafía o la arqueología, cualquier tipo de aproximación cronológica a estos restos provendrá del análisis relativo de las estratigrafías murarias y del establecimiento de paralelos con otras fábricas así construidas. A este respecto se puede reseñar la falta de vínculos con obras romanas y otras de origen bajomedieval, mientras que, por el contrario, es evidente su afinidad con algunas estructuras cuyo origen se acostumbra a definir de forma genérica en periodo omeya. Concretamente, el paralelo más importante que disponemos será el del castillo de Trujillo, en el que la fase inicial de sus muros se construye de manera idéntica a ésta que presentamos en la fortaleza de Medellín. También podemos apuntar la semejanza con algunas fábricas estudiadas en las defensas urbanas de Toledo, Vascos o Talavera. Otras construcciones menos cuidadas diferirán en la definitiva puesta en obra de las piezas, sobre todo al carecer de las anchas cintas biseladas que incluyen pequeñas placas, y que veíamos en los otros casos. Dentro de este último grupo podemos señalar los ejemplos de Mérida, Coria o Castros. El concepto tecnológico que se deriva de estas prácticas, próximas a procedimientos de albañilería ${ }^{36}$, y basadas en el escaso desarrollo del trabajo de cantería (que se reduce aquí al sim- ple acarreo y posterior recalce de las piezas), será común a este heterogéneo conjunto de obras militares que se sitúan en un área específica de las Marcas Media e Inferior.

En definitiva, la repercusión del hallazgo que publicamos sobrepasa el propio conocimiento arqueológico del castillo de Medellín para hacernos reflexionar sobre ciertos aspectos de la construcción en la periferia de al-Andalus durante época omeya. Insistimos en que la especial sectorización que se deriva de estas prácticas edilicias permite sugerir el arraigo de las mismas a través de hipotéticos equipos o talleres regionales más o menos estables. Ahora bien, aunque podamos concluir que las primeras estructuras de esta fortaleza extremeña se construyeron o reconstruyeron posiblemente en algún momento durante los siglos IX $\circ X$ (margen sobre el que disponemos de información complementaria de los textos y de la cerámica), la coyuntura exacta que motivó la intervención de dichos especialistas en Medellín nos es absolutamente desconocida, al igual que ocurre en la mayoría de los casos referidos. $Y$ es que, posiblemente, estas prácticas fueran de común recurso en este territorio durante todo el periodo considerado, incluso por parte de la autoridad cordobesa cuando ésta las necesitara para sus obras.

Hemos de agradecer a la arqueóloga Sophie Gilotte su indispensable información sobre la historia y la arqueología de Medellín, y al arquitecto Juan Ignacio Rosado Feito los datos proporcionados sobre la topografía de la fortaleza.

36 J. A. QUIRÓS CASTILLO, op. cit., 2002, pp. 281 a 282. 


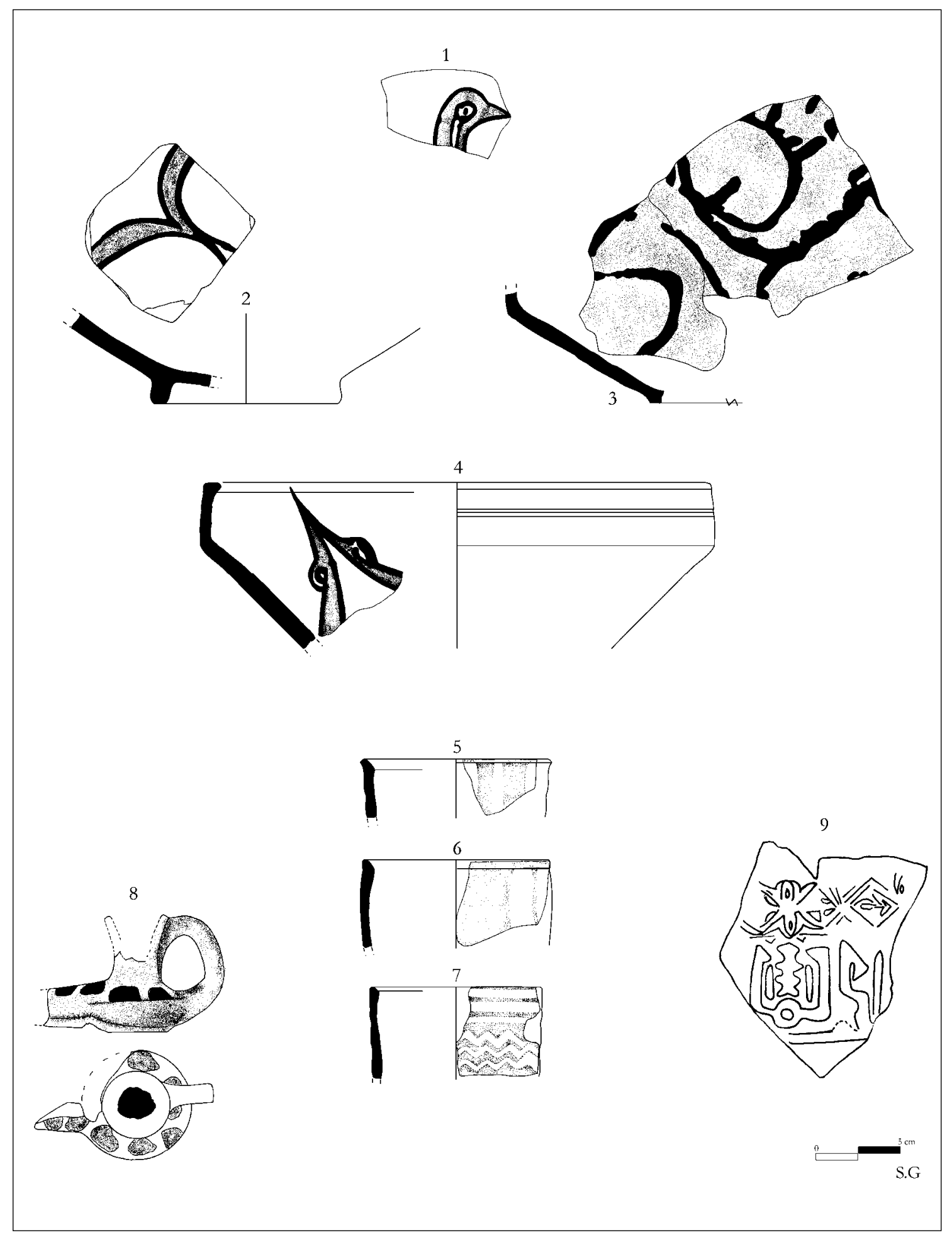

Figura I. Medellín (excavación del teatro romano (1975). I- Fragmento de ataifor con vedrío verde y manganeso y motivo zoomorfo ( $m$. X-XI); 2- Fondo de ataifor con vedrío verde y manganeso ( $m$. $X-X I)$; 3- Fondo de ataifor con vedrío melado y manganeso; 4- Ataifor con vedrío verde y manganeso (f. XII-XIII); 5,6 y 7- Cuellos de jarritas con bordes biselados al interior y decoración de pintura blanca (ss. X-XI); 8- Candil de piquera con goterones verde oscuros ss. X-XI); 9- Fragmento de tinaja con decoración estampillada (f. XII-XIII). Dibujos de Sophie Gilotte. 

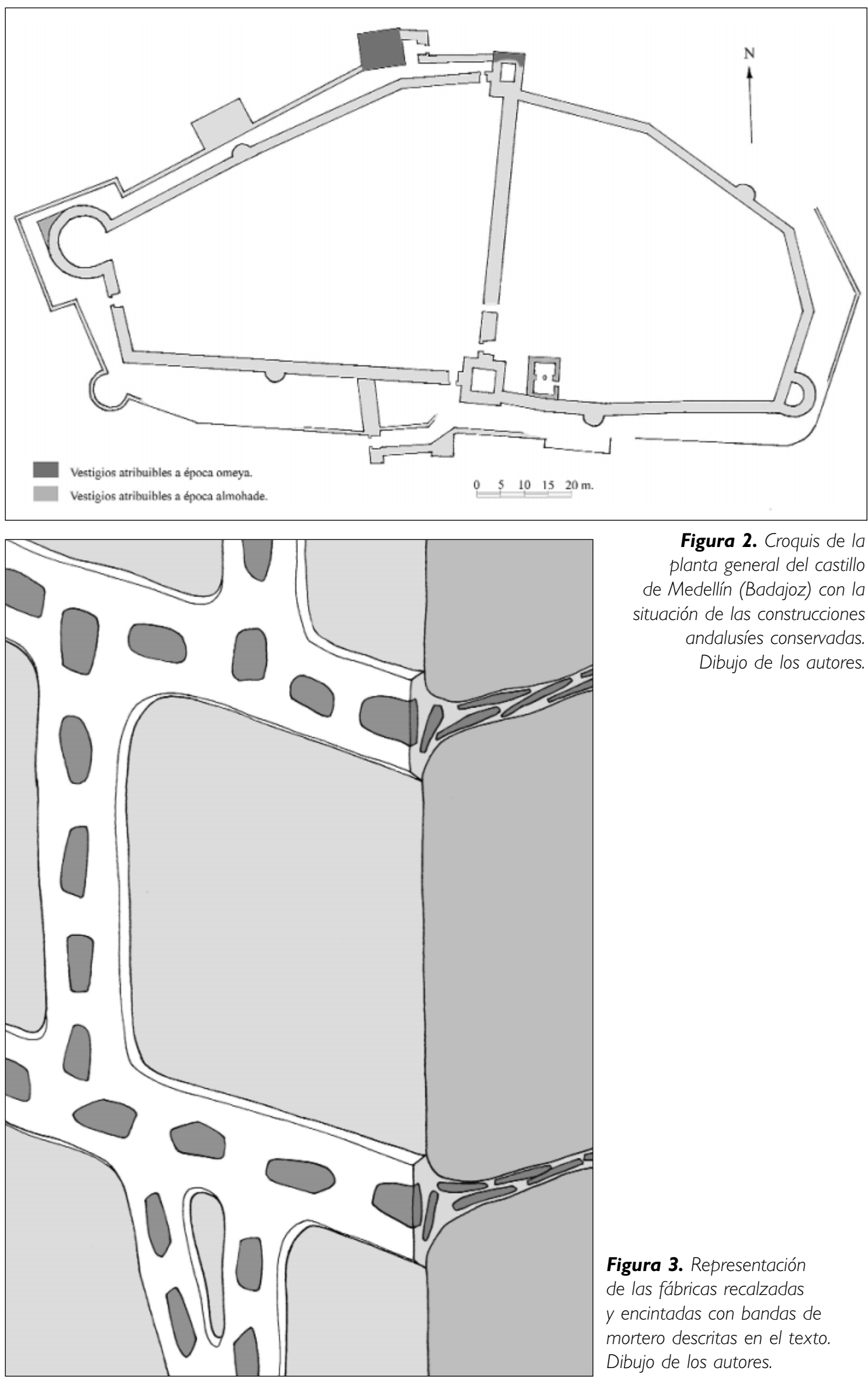

Figura 2. Croquis de la planta general del castillo de Medellín (Badajoz) con la situación de las construcciones andalusíes conservadas. Dibujo de los autores.

Figura 3. Representación de las fábricas recalzadas y encintadas con bandas de mortero descritas en el texto. Dibujo de los autores. 


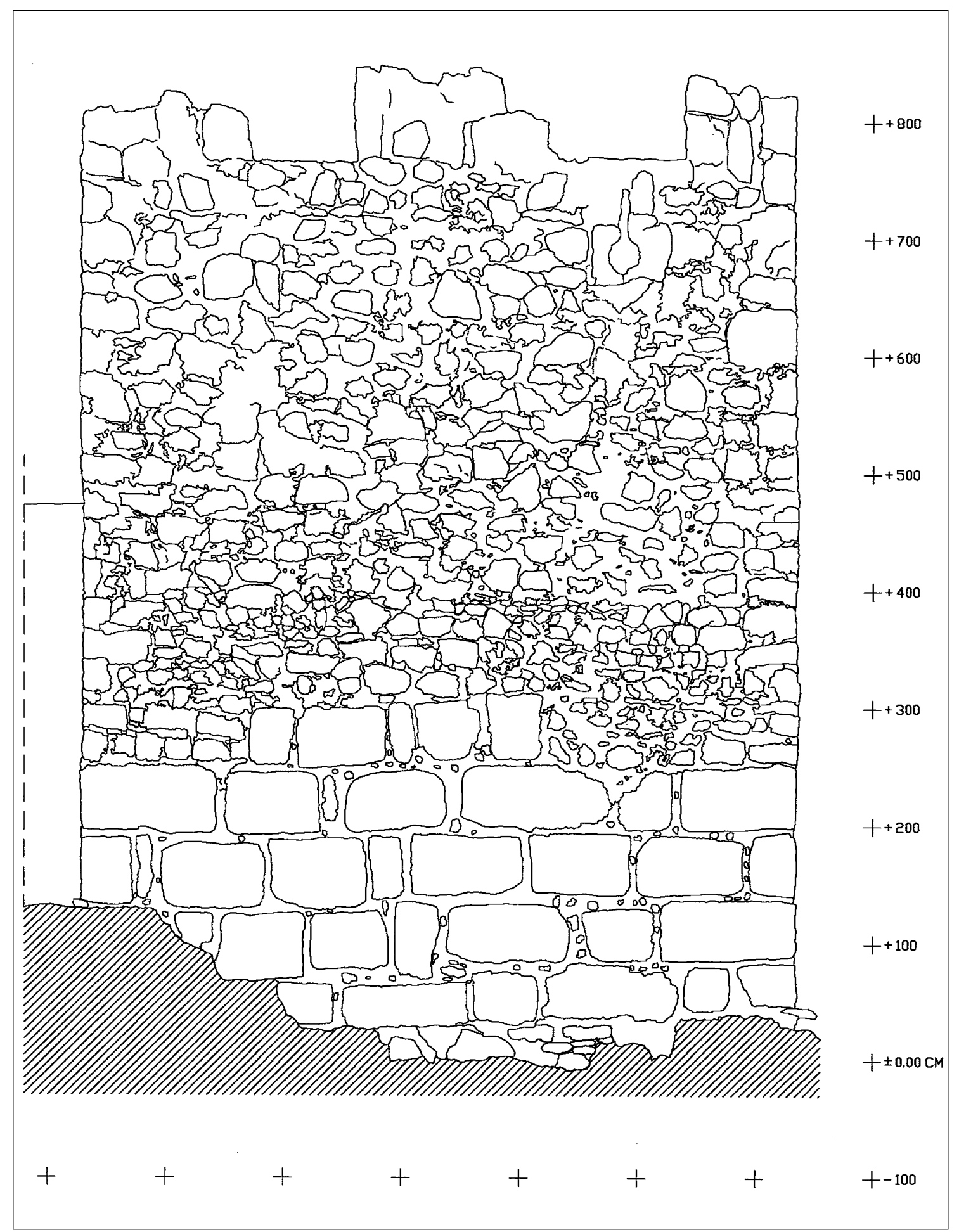

Figura 4. Alzado norte (A. I.) de la torre del acceso acodado en el antemuro septentrional del castillo de Medellín. Dibujo de los autores. 


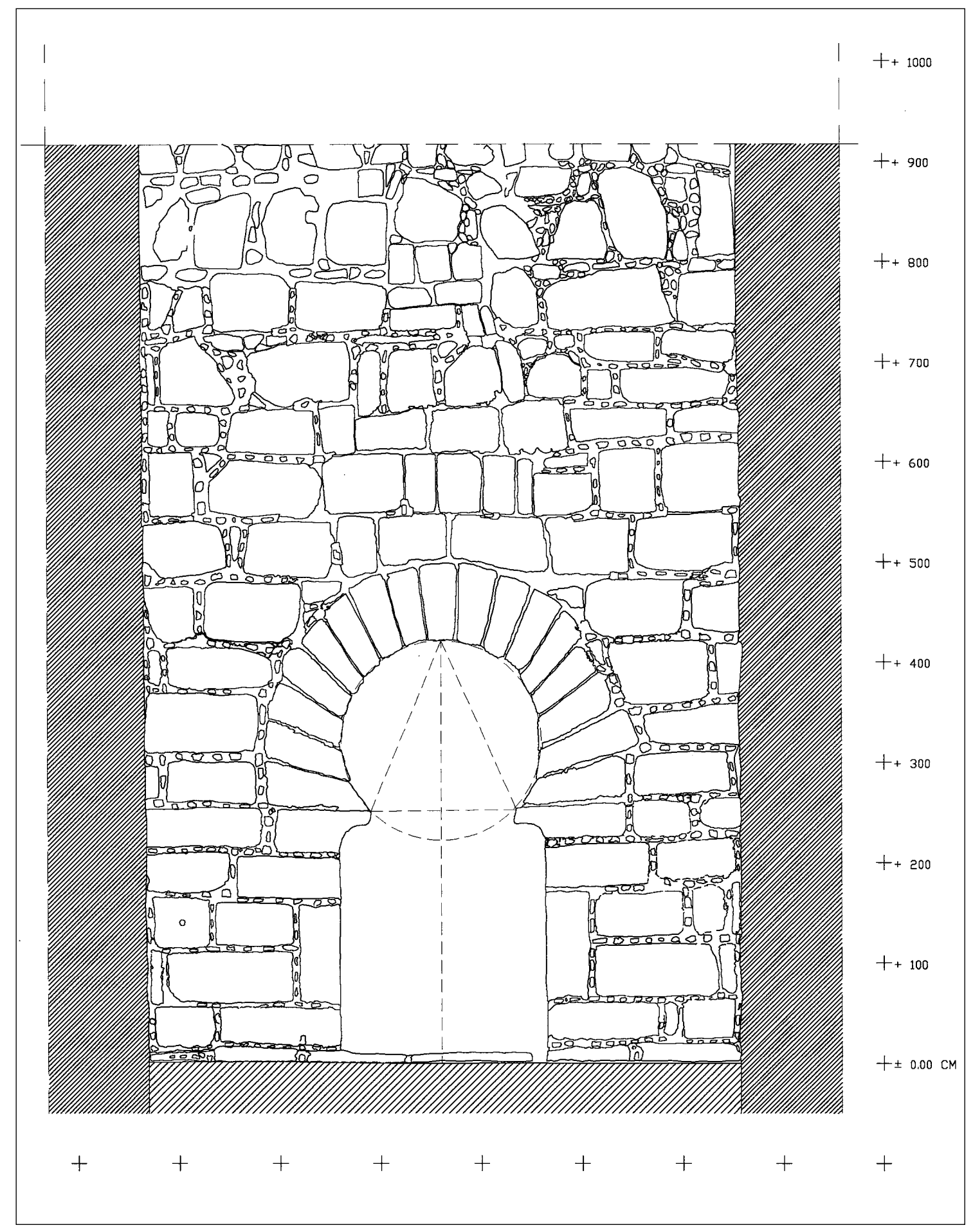

Figura 5. Alzado exterior de la puerta de acceso principal al castillo de Trujillo (Cáceres). Dibujo de los autores. 


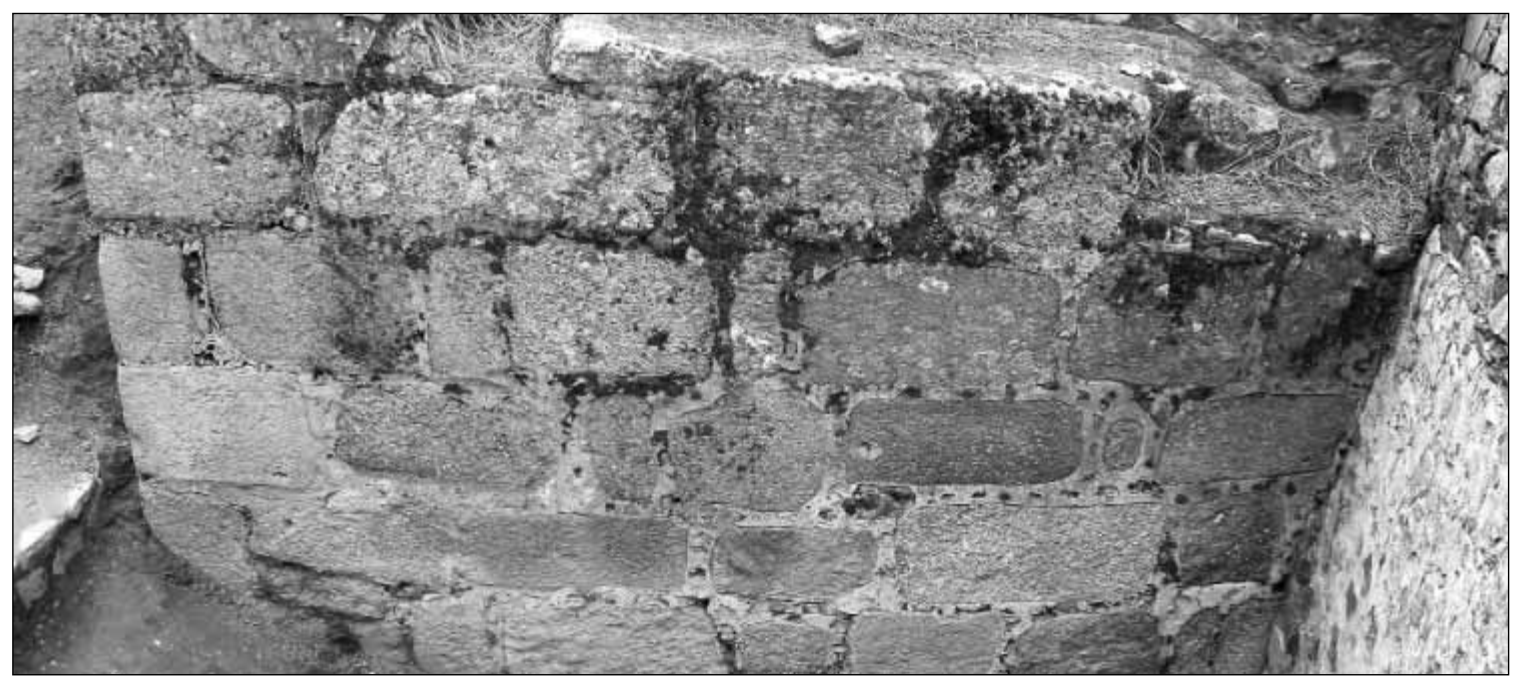

Lámina I. Fotomontaje de las fábricas situadas en la cara oriental de la torre del acceso acodado en el antemuro septentrional (A.2.).

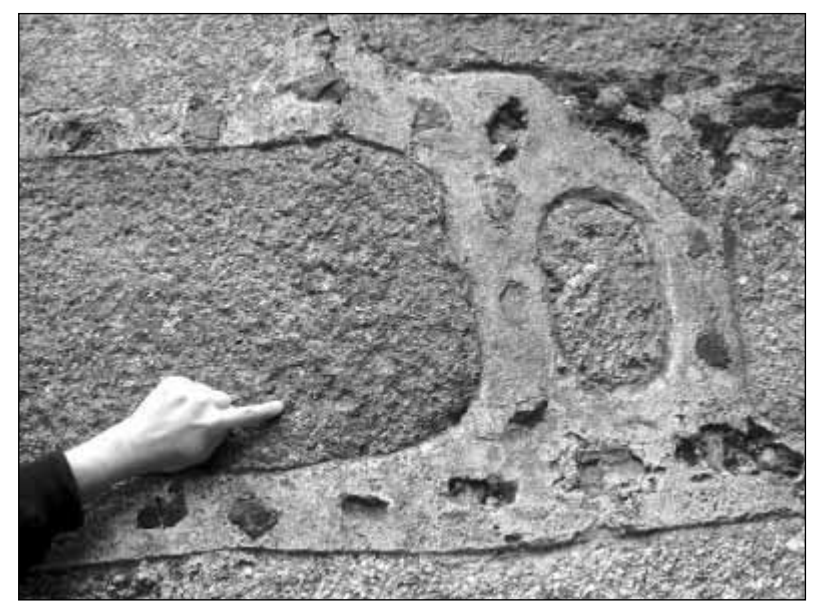

Lámina 2. Detalle de las cintas biseladas y los pequeños fragmentos de pizarra puestos de plano en las fábricas del muro A.2

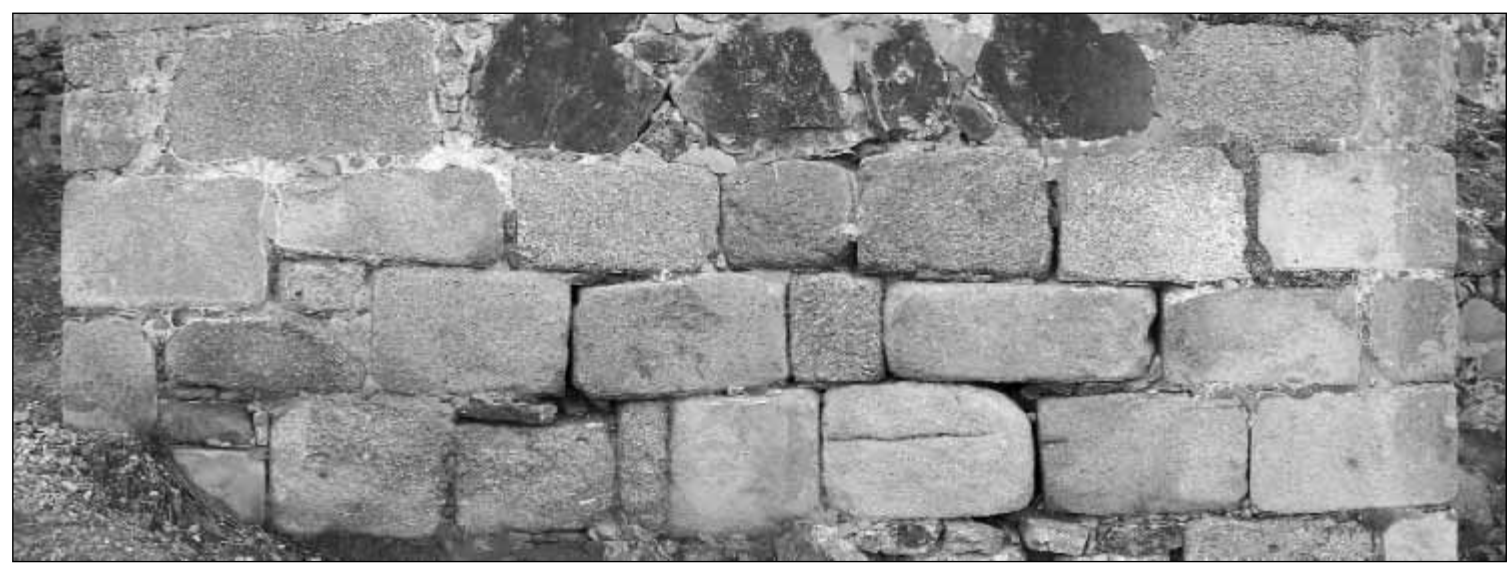

Lámina 3. Fotomontaje de las fábricas situadas en la cara norte de la torre cuadrangular septentrional de la fortaleza (B.I.)" 
Lámina 4. Detalle de las sillerías encintadas en el castillo de Trujillo (Cáceres).
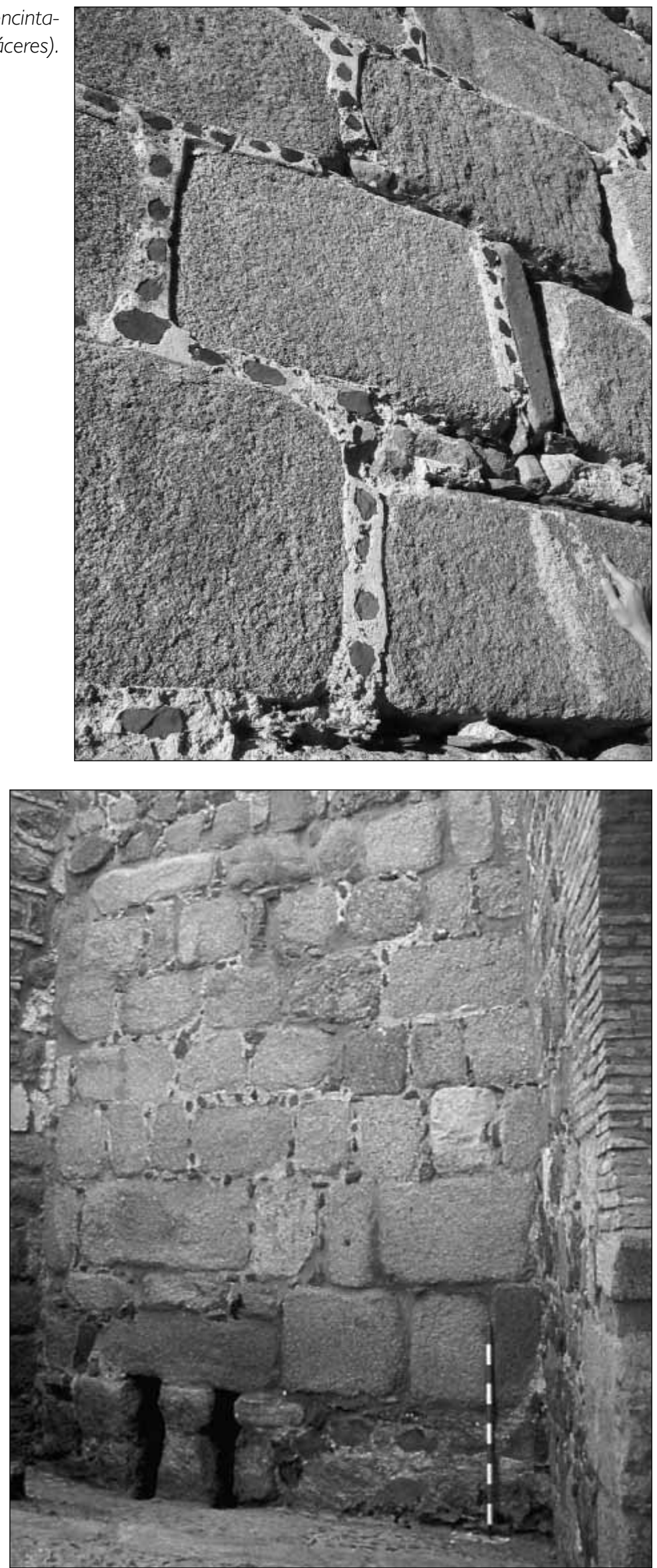


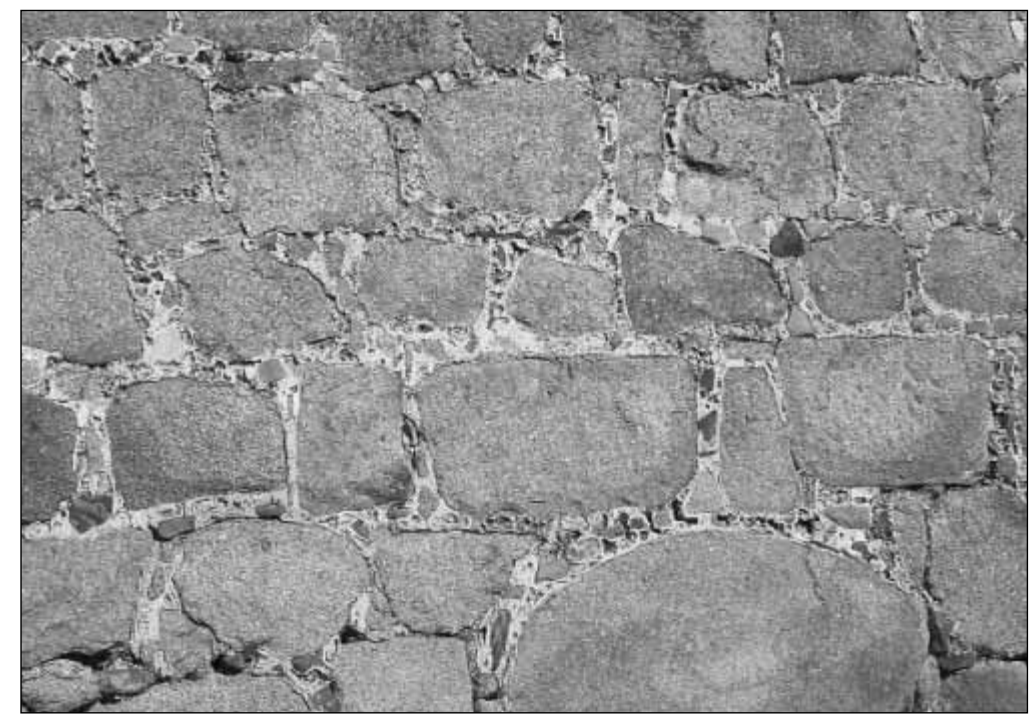

Lámina 6. Detalle de las fábricas encintadas del frente meridional de la madina de Vascos (Toledo). Obsérvese la inclusión de numerosos fragmentos cerámicos colocados de cara"

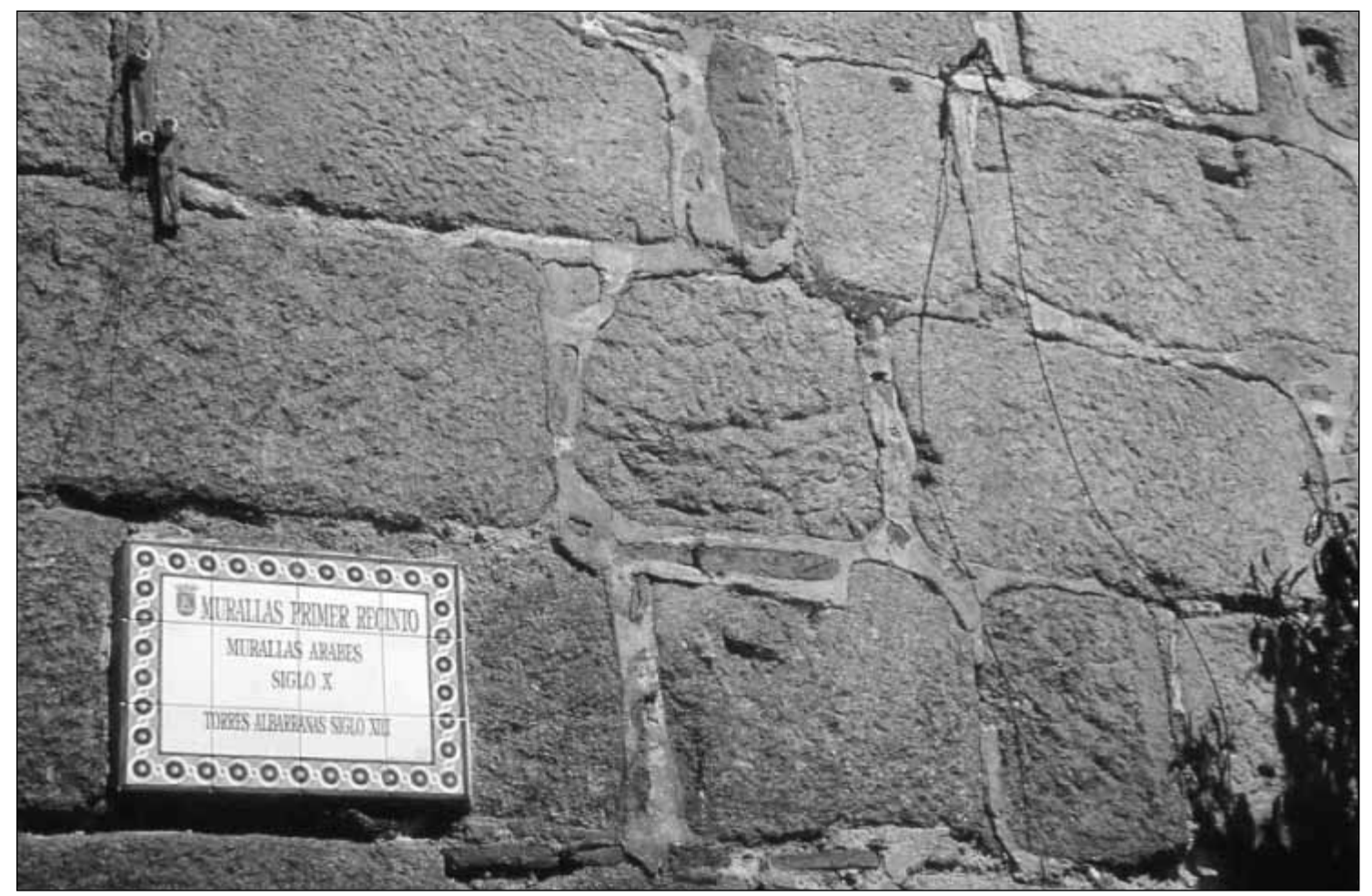

Lámina 7. Detalle de la cara meridional de la torre de ángulo SE de la alcazaba de Talavera (Toledo). 